\title{
El proceso procreativo y la concepción de la persona en el pueblo ticuna del Amazonas peruano
}

\section{Selva Sofia Chirif}

(iD) https://orcid.org/0000-0002-2016-1691

Ministerio de Educación del Perú

schirif@gmail.com

RESUMEN

A lo largo de la última década se observa un creciente incremento en la ejecución de programas materno-infantiles basados en concepciones biomédicas. A partir de una investigación etnográfica realizada en comunidades del pueblo ticuna, argumento la necesidad de que estos programas dialoguen con las nociones indigenas sobre cuidados durante el proceso procreativo, reconociendo la existencia de diversas formas de concebir a la persona y su incidencia en las maneras de entender la concepción y las prácticas de cuidado del embarazo, parto y puerperio. Este artículo busca profundizar la forma como el pueblo ticuna concibe la construcción de la persona y su influencia en cada fase del proceso reproductivo, describiendo el rol que cumplen diferentes agentes humanos y no humanos. La investigación etnográfica combinó la observación participante, conversaciones informales y entrevistas semiestructuradas a mujeres y hombres de distintas edades. La información recogida se analizó con la técnica de la cronografía procreativa propuesta por Lázare y Fons (2016) que permite identificar las etapas del proceso procreativo desde el punto de vista exegético.

Palabras clave: ticuna, proceso procreativo, sangre, noción de persona, cronografía procreativa. 


\title{
Procreation and personhood among Ticuna indigenous peoples in the Peruvian Amazon
}

\author{
ABSTRACT
}

During the last decade there has been an upsurge in the development of mother-child programs based on biomedic conceptions. Drawing on ethnographic material from research with Ticuna indigenous people, I call for the need for dialogue between these programs and indigenous notions of personhood recognizing their influence on the understanding of conception and childcare practices. In this chapter, I explore how Ticuna people conceive the way in which the person is shaped and its influence on each stage of the reproductive cycle, describing the role that different human and non human agents play in this process. Ethnographic research combined participant observation, informal conversations and semi structured interviews with women and man of different ages. This information was analysed with the procreative chronographie technique proposed by Lázare and Fons (2016), which helps to identify the different stages of the procreation cycle from an exegetic point of view.

Keywords: Ticuna, human procreation, personhood, spiritual care, methodology of procreative chronographie. 


\section{INTRODUCCIÓN}

La visión holística de sociedad y naturaleza de los pueblos indígenas amazónicos influye en los cuidados que reciben las personas sobre todo durante el proceso de embarazo y puerperio. Diversas investigaciones dan cuenta de las distintas miradas ontológicas con relación a la formación de la persona. Uno de los referentes sobre el tema es el artículo de Anthony Seeger, Roberto DaMatta y Eduardo Viveiros de Castro (1976), que condensa los avances etnográficos de la época sobre la corporalidad y la noción de persona construida por medio de la elaboración de su cuerpo.

Santa Rita de Mochila, Nueva Galilea, Santa Cecilia, Cushillo Cocha y Bufeo Cocha fueron las cinco comunidades ticuna, ubicadas en el departamento de Loreto, Perú, donde trabajé entre los años 2013 y 2016. Durante este tiempo coordiné el Proyecto de Formación Intercultural para el Desarrollo Integral y el Cuidado de la Primera Infancia de la Amazonía peruana, colombiana y boliviana, ejecutado por el Ministerio de Educación de Perú y la Organización de Estados Americanos con los pueblos indígenas ticuna, yagua y kukama, ubicados en la frontera entre Perú, Colombia y Brasil. Este trabajo me permitió acercarme a la existencia de otra forma de concebir a la persona y el proceso procreativo, que se aleja de la concepción biomédica de embarazo, parto y puerperio, y diferencia cuatro etapas en función de la importancia que tiene la sangre como principio nuclear de la formación de la persona y la manera como se va transfigurando en cada una de ellas.

En este artículo doy cuenta de la visión ticuna sobre estos procesos y la manera como dialogan o no con las prácticas de los programas materno-infantiles. Desde esta aproximación pretendo vincular los importantes avances etnográficos que se han realizado sobre la formación del ser con la manera como estas concepciones se relacionan con las prácticas de crianza en ámbitos indígenas amazónicos. Así busco superar la tendencia de algunos estudios sobre crianza, que se limitan 
a presentar un listado de las prohibiciones y prescripciones alimenticias y conductuales que orientan la práctica de los pueblos indígenas durante el proceso procreativo, sin explicar las causas o significados que las sustentan. Como se tratará de explicar en este artículo, estas se vinculan con la visión que se tiene sobre la persona y la ubicación del ser humano en el cosmos.

\section{METODOLOGÍA}

Entre los años 2013 y 2016 realicé visitas mensuales a cinco comunidades del pueblo ticuna.

Durante ellas recogí información importante sobre prácticas de reproducción y crianza de los niños y niñas menores de tres años. La investigación etnográfica combinó la observación participante con notas in situ, largas conversaciones informales y entrevistas semiestructuradas a mujeres y hombres de distintas edades, así como registros fotográficos y grabación de entrevistas ${ }^{1}$.

Como criterio de selección, opté por trabajar con mujeres madres que habían parido por lo menos una vez en la comunidad. Por lo general tenían más de veintitrés años. Las abuelas y las parteras fueron personas claves, ya que por su gran conocimiento del proceso procreativo aportaron información relevante para los fines de la investigación. Si bien los varones participaron en menor medida, muchos de ellos eran grandes conocedores de técnicas y posiciones para dar a luz por haber acompañado los partos de sus esposas. Asimismo, fueron ellos quienes me explicaron el porqué de ciertas prácticas haciendo alusión a los relatos de origen. Los talleres de formación de líderes y de promotoras educativas comunitarias en los que participé me permitieron, además, contrastar la información recogida y profundizar algunos temas.

Para el análisis de la información, he utilizado la técnica de la cronografía procreativa propuesta por Lázare y Fons (2016), que permite estudiar profundamente el proceso reproductivo, y, además, analizar las formas como se establecen los cuidados durante el embarazo y puerperio, así como las formas de parentalidad que surgen de estos cuidados. La cronografía procreativa explica lo que sucede en un espacio temporal, otorgando significado a los elementos que van apareciendo durante el proceso procreativo y cómo estos se van agrupando, con el fin de constituir «unidades de sentido» significativas en la procreación para una sociedad. Tal como lo explican Fons y otros (Fons, Casado, Imaz, Lázare y Sáez, 2019, p. 394):

\footnotetext{
1 Se ha utilizado Atlas Ti y el programa RQDA para categorizar y codificar los datos.
} 
La cronografía procreativa [...] permite entrever de forma procesual y detallada el entramado de aspectos sociales y culturales que conforman sistemas de pensamiento sobre el acto de crear una persona, promover su nacimiento y su supervivencia, así como adscribirla a un grupo responsable de su cuidado.

Asimismo, permite identificar las etapas del proceso procreativo desde el punto de vista exegético o nativo, es decir, no divide la procreación en embarazo, parto y postparto como se nos ha presentado desde la medicina (Lázare y Fons, 2016). En tal sentido, la cronografía procreativa me ha resultado de gran ayuda para analizar el significado que se le otorga a la sangre y cómo esta se va articulando con otros elementos que permiten la construcción de la persona ticuna, a través del proceso procreativo. En este proceso de análisis me fue muy útil el trabajo de Luisa Elvira Belaunde con el pueblo Airo Pai y la recopilación que hace en su libro El recuerdo de Luna (Belaunde, 2008), en el cual explica el significado de la sangre derramada durante la menstruación, el parto, la guerra y la cacería, así como la influencia del flujo de sangre en la construcción del cuerpo.

\section{LA CORPORALIDAD AMAZÓNICA}

La idea de que la persona social es construida mediante la formación de su cuerpo (sus fluidos, ornamentación, habilidades, etcétera) constituye el referente teórico básico de la antropología amazónica.

Desde las cosmologías de los pueblos indígenas de América del Sur, el cuerpo es la base para la construcción de las personas, pero este no solo es físico ni tampoco representa la totalidad de la persona. Seeger y otros (1987) explican que la producción física de los cuerpos tiene que ver con la producción social de las personas, como miembros de una sociedad específica: «El cuerpo, afirmado o negado, pintado o perforado, recluido o devorado, tiende siempre a ocupar una posición central en la visión que las sociedades indígenas tienen de la naturaleza del ser humano» (Seeger, DaMatta y Viveiros del Castro, 1987, p. 4).

Tal como muestran diversas etnografías realizadas en las tierras bajas de América del Sur, el cuerpo es un proyecto colectivo debido a que es socialmente transformado. Tola (2012) afirma que «el cuerpo de una persona no suele constituirse individualmente sino que requiere de un colectivo para hacerse» (Tola, 2012, p. 309). Este colectivo involucra tanto a seres humanos como no humanos, ya que desde las ontologías amerindias no establecen oposiciones entre unos y otros, sino que forman parte de un mismo colectivo. 
Un aporte significativo en el tema de la construcción de la persona amerindia es sin duda el de DaMatta, quien explica que la persona se cimenta mediante un proceso de consustancialización al compartir sustancias: comida, fluidos corporales, olores y recuerdos recibidos (Berjón y Cadenas, 2014, p. 10). Esto es, sin duda, lo que los diferencia de los otros seres y lo que los emparenta con los suyos ya que, según Viveiros de Castro (2004), el compartir fluidos corporales, sexuales y alimenticios te relaciona con los tuyos a través de un proceso activo de asemejamiento. De este modo, podemos observar que, en el pensamiento amazónico, la persona se va construyendo a través de acciones y elementos propios de los humanos, como adornos, amuletos, leche materna y curaciones tradicionales, y de los no-humanos, como curaciones chamánicas, $\operatorname{arcanas}^{2}$ y otras prácticas.

\section{LOS TICUNA}

El pueblo ticuna se ubica a lo largo de río Amazonas en una extensión de $600 \mathrm{~km}$, entre la desembocadura del río Atacuari en el Perú y la del río Jutaí en Brasil. Se estima que su población es de entre 30000 (Goulard, 1994) y 40000 personas (Vieco, Franky y Echeverri, 2000, p. 111) entre el Perú, Colombia y Brasil. En el Perú, los ticuna se encuentran principalmente en el departamento de Loreto.

Los ticuna se dividen en clanes de dos tipos: los sin plumas, que albergan a especies vegetales y animales terrestres, y los con plumas, aves. Se dice que antiguamente no tenían clanes y todos eran aves, «todos eran ko-ü, tatatao» (aves) (Goulard, 1994, p. 258). Una infracción de los gemelos míticos es lo que produjo la diferenciación clánica, sumando más de cincuenta y tres.

La pertenencia a un clan es una condición ticuna y se transmite por vía patrilineal. Todos los miembros de un clan son familia y poseen la misma sangre, por esto no pueden casarse con personas del mismo clan. De hacerlo estarían cometiendo incesto.

2 La arcana es una curación realizada por los chamanes que consiste en ponerle al bebé el espíritu de animales fuertes, como el oso hormiguero, el jaguar, el mono negro, etcétera. Estas protecciones se realizan durante los primeros años de vida y ayuda a que los niños resistan enfermedades y dificultades que se presenten en su vida, según las características del ser o espíritu que le designa el curandero (Formabiap, 2008). 


\section{EL PROCESO DE CONSTRUCCIÓN DE LA PERSONA EN EL PUEBLO TICUNA}

\section{La construcción de la persona a través de los rituales}

Goulard (2009) señala que el ser está formado de tres principios, el pora (fuerza), el $m a-\tilde{u}$ (principio corporal) y el $a-e$ (principio vital). Estos principios fundamentales son los que rigen el territorio, cuerpo y cosmos, es decir al naane (Santos, 2014). Es así que todos los seres, humanos y no humanos visibles o no visibles se originan por estos principios.

Los ticuna practican ciertos ritos para incrementar estos principios, para proteger el cuerpo, o parte de él y para establecer relaciones con los seres del cosmos. Estos se llevan a cabo en diferentes espacios, como la chacra, el río, las lagunas, las quebradas, a diferentes horas del día, en distintas fases de la luna y épocas del año. Desde la concepción ticuna, el cuerpo está interconectado al territorio por medio de los tü (red de hilos de humo de tabaco) que forman el cuerpo, por el que entran y salen energías positivas y negativas (Santos, 2014).

El ma- $\tilde{u}$ (principio corporal) es proporcionado por el nacimiento, es lo que le da la posibilidad de existir a la persona, es inmutable y es lo que determina y funda su identidad (Goulard, 2009, p. 89). El pora también está asociado al principio corporal debido a que «sin él no hay posibilidad de su inscripción en el medio ambiente» (Goulard, 2009, p. 71). Santos (2014) agrega que si el pora

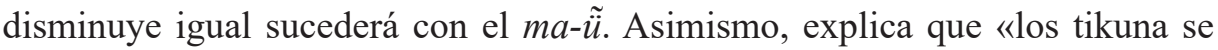
refieren con $m a-\tilde{u}$ al estilo de vida o al sello cultural, pero también es la identidad personal, es el comportamiento o la forma de actuar y de vivir de la persona» (Santos, 2014, p. 332). El pora es la energía que tiene todo ser.

El $a$-e (principio vital) está asociado al pora (fuerza), ya que sin el $a$-e el pora no existe. El pora es el que da fuerza al cuerpo y es continuamente renovado ya que es alterable. Goulard (2009) menciona que «la asociación del pora y del principio vital se privilegia en el discurso indígena: el principio vital tiene pora que sirve al cuerpo para tener la fuerza» (Goulard, 2009, p. 71).

El pora se asienta en el ma-ũne (corazón), ya que al ser productor de sangre lleva la característica del principio vital y se apoya en este. Del pora va a depender la calidad de la sangre, «líquido que regula numerosas relaciones de la vida cotidiana de los ticuna» (Goulard, 2009, p. 71). Cada ser vivo nace con un pora mínimo que le permite subsistir, este se va fortaleciendo a lo largo del ciclo vital mediante la alimentación y los rituales de paso. Los animales y algunas plantas son los que abastecen a los humanos de pora mediante la alimentación. Estos también 
tienen pora, pero unos tienen más pora que otros. Al respecto, Santos (2014) agrega que la persona obtiene su pora (fortaleza) del pora de ciertos alimentos; la adquisición de pora depende de la edad, el tiempo, el espacio, el momento y la capacidad anímica. En algunos momentos (como durante el embarazo, puerperio, menstruación, etcétera) se tiene que hacer dietas y consumir alimentos con bajo pora debido a que en estos momentos el pora de la persona ha disminuido y su adquisición debe ser cuidadosa y sincronizada (Santos, 2014). Otra forma de abastecerse de pora es mediante la masateada, que es la ingesta de chicha de yuca (Manihot esculenta) en actividades sociales (Goulard, 2009).

Los ritos de paso también constituyen una forma de fortalecer el pora. El pora necesita ser renovado y restaurado (en caso de enfermedad); si esto no se hace, los diferentes seres del cosmos pueden atacar y ocasionar la muerte. Los ticuna practican diferentes rituales y acciones que favorecen el cuidado, protección y formación del cuerpo y de la persona (Santos, 2014). Estas acciones se inician durante la gestación y pasan por todas las etapas de la vida.

\section{El ritual de la pubertad: Woxrexcüchiga}

Uno de los rituales más importantes es el de la pubertad o de la woxrexcüchiga, que significa «moza con los senos en brote» (Camacho, 1995, p. 8; citado por Belaunde, 2016, p. 16). Tradicionalmente se ha practicado este rito. Sin embargo, actualmente ha sido abandonado en muchas comunidades por efecto de la religión.

Durante la primera menstruación, la púber se encuentra en un estado de maduración. En estos momentos su pora (fuerza) ha disminuido, por lo que su $a-e$ (principio vital) se encuentra más vulnerable. Ella no pertenece al mundo de los humanos, por eso es necesaria su reclusión y su aislamiento físico (Goulard, 2009, p. 170).

Durante la reclusión, la woxrexcü escucha los consejos de su madre y otras mujeres, aprende a tejer, hilar y guarda ayuno. Ellas también se encargan de arrancarle el cabello. Esto es muy importante, ya que supone renovación y transformación de la woxrexcü.

El último día de la reclusión se prepara una gran fiesta en la que abunda la comida y la bebida. En esta participan los espíritus ngoxogü, que vienen a la fiesta vestidos con su ropa de corteza de árbol. Para los ticuna estos no son disfraces sino sus cuerpos espirituales: «quien aparece vestido con una máscara de corteza es un espíritu venido de otros mundos» (Belaunde, 2016), asociado a la idea de que la forma material con la que aparece es un envoltorio que esconde su 
humanidad (Viveiros de Castro, 2004). Los espíritus que vienen tratan de raptar a la niña para llevarla a su mundo. Sin embargo, al final desisten y se unen a bailar con los pobladores, momento en el cual se disuelve la distancia que los separa de los vivos.

Otro aspecto importante es la pintada del cuerpo de la púber con huito el último día de la fiesta: «después de bailar con los espíritus, la niña toma un baño en el río y sale del agua con el cuerpo teñido de la cabeza a los pies, como una recién nacida» (Belaunde, 2016, p. 17). El huito ocupa un lugar importante en la cosmología ticuna y es utilizado en los rituales de nacimiento y renacimiento. «Al pintarse el cuerpo con genipa, los ticuna señalan su estado de seres humanos» (Goulard, 2009, p. 173). Según la mitología ticuna, ellos nacieron de la carne del fruto del huito.

\section{La construcción del cuerpo ticuna durante el proceso procreativo}

He dividido el proceso procreativo ticuna en cuatro etapas según el significado que tiene la sangre y la adquisición del pora en cada uno de los periodos.

- Primera etapa de preparación y colaboración de «sangres»: la concepción, vientre con cría na aãxcü.

El canto de ciertas aves o los sueños es un indicio del embarazo. Una mujer ticuna me contaba que «uno sueña con pollito o con sandía. Si eso sueñas es que estás embarazada». Rivas (2016) asegura que «la confirmación de que una mujer se encuentra embarazada ocurre cuando algunos animales, como el búho o la lechuza, cantan cerca de la casa» (Rivas, 2016, p. 25). Para indicar que el proceso de gestación se ha iniciado, dicen que la mujer «tiene cría en el vientre», na aãxcü.

El bebé se forma de la sangre femenina y de la sangre masculina en forma de semen. Según la concepción ticuna, las mujeres son las que hacen a las niñas y los hombres a los niños. Esto dependerá de la fuerza de cada sangre en el momento de la concepción. Varias mujeres ticuna con las que trabajé me contaron que para saber el sexo del bebé hacían un tajo en forma de cruz con un cuchillo en el corazón de un pollo y lo metían en el agua hirviendo. Si se abría como una vagina significaba que iba a ser niña, si permanecía cerrado como pene significaba que sería niño.

Desde pequeñas, las mujeres son preparadas y aconsejadas por sus madres y abuelas para asumir los procesos de gestación y parto. Al respecto, Rosmery me contó: 
Mi mamá cuando era chiquita me decía que no deje amontonada la basura que yo barría, ¿di? ${ }^{3}$, porque si no cuando tenga mi $l l u l l o^{4}$ no iba a nacer rápido. Por eso nosotras las ticuna somos limpias, nunca dejamos la basura amontonada. Así nos han enseñado nuestras abuelas. Tampoco, se vale lamer lo que

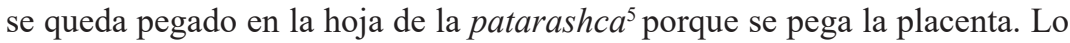
mismo sucede con el arroz que se pega al fondo de la olla. No se puede comer concolón ${ }^{6}$ del arroz porque, si no, cuando vas a dar a luz, igualito el bebito se queda pegado en tu barriga.

- Segunda etapa (entre uno y tres meses) en la que engorda: taaãxkü, es decir «barriga pequeña»

En la concepción ticuna, el bebé se va formando a partir de la sangre de la madre y con el aporte de la sangre del padre (semen). Ambas sustancias se mezclan a partir de las relaciones sexuales continuas. De esta manera el bebé va creciendo, llenándose de sangre. Goulard (2009) señala que «el esperma (namũ) del hombre asegura el alimento del «grano» (nachire) con las relaciones sexuales, cuya repetición se considera necesaria para alimentar el embrión (Goulard, 2009, p. 134). Belaunde (2008) asegura que «al crecer, los niños y las niñas van adquiriendo más sangre, voluntad y conocimientos hasta llegar a la pubertad» (p. 44).

El semen alimenta al bebé, le da pora (fortaleza) para que se ponga de pie rápidamente. Sin embargo, los padres deberán tener en cuenta ciertas conductas y evitar el consumo de alimentos con mucho pora, es decir, aquellos que tienen mucha sangre o grasa, debido a que el bebé en crecimiento tiene poco pora y el exceso de este podría afectarlo. En un viaje en bote por el Amazonas, una mujer ticuna me contaba las dietas que se tenían que hacer durante la gestación para no afectar al bebé: «cuando comes carachama ${ }^{7}$, te va bajar bastante sangre. Así también si comes macana ${ }^{8}$ o anguila ${ }^{9}$. La anguila es más peligrosa. Esa le mata al bebé».

3 Di. (Cast.) Expr. Muletilla empleada por una persona para interrogar a su interlocutor sobre una sentencia previa. En realidad, más que interrogar se emplea para dar por sentada la sentencia y pedir que la interlocutora la reafirme. Por ejemplo: «No vas a ir, ¿di?» (Chirif, 2016).

4 Bebé.

5 Comida de la selva del Perú que consiste en envolver el pescado en ciertas hojas y asarlo en el fuego de leña o carbón.

6 Costra del arroz semiquemada que queda adherida al fondo de la olla.

7 Pseudorinelepis genibarbis. Pez con apariencia de animal prehistórico. Se aplica a diversos peces del género Hypoptopoma sp.

8 Reciben este nombre una variedad de peces de la familia Apteronotidae.

9 Peces de cuerpo alargado de la familia Anguillidae. 
Otra forma de protección es que las mujeres dejan de ir al monte debido a que se pueden cutipar ${ }^{10}$ o caerse y abortar. Tal como menciona Goulard (2009), «la agresión de las entidades que pueblan el monte puede tener graves consecuencias». En una de mis visitas a la comunidad Santa Cecilia fui a visitar a una mujer embarazada muy joven. Cuando llegué, las mujeres de la casa iban de camino a la chacra a recoger yuca. Al preguntarle por qué ella no iba, me comentó que su abuela le había dicho que si iba a la chacra tuviese cuidado de no pasar por debajo del árbol de la lupuna, ya que si eso sucedía, su bebito podía nacer sin huesos. Entonces ella había decidido no ir.

- Tercera etapa dirigida a la preparación del parto (desde los cuatro meses hasta el parto): tacharaü, «barriga grande»

En esta etapa, la construcción de la persona se realiza mediante los cuidados corporales y espirituales, a partir de las restricciones y prescripciones alimenticias y conductuales impuestas a los padres. Si estos no las cumplen, el $a-e$ (principio vital) puede salir del cuerpo del bebé y quedarse vagando en el cosmos, lo que puede causar la muerte del feto (Goulard, 2009).

A diferencia de la etapa anterior, en esta las mujeres se cuidan de no engordar para evitar un parto complicado. En una conversación con mujeres de la comunidad Nueva Galilea de Cayarú sobre los servicios de Salud del Estado durante el embarazo, una mujer me explicó:

Las vitaminas ${ }^{11}$ que nos da la posta ${ }^{12}$, yo le guardo nomás, eso nos engorda, dice que nos da sangre. Yo cuando estaba embarazada, cuando vienen acá, la doctora me examina mi barriga. Pero irme allá, iyo no me voy! Nos dan vitamina, pero le guardamos, nomás, porque nos engorda. Según ellos, nos dicen para tomar, para tener sangre, pero yo no tomo y acá la mayoría no toma. Inútil es que les den porque para ${ }^{13}$ guardado nomás. Reciben, pero luego le botan. El bebé engorda mucho con esas vitaminas.

La etapa de engorde, de llenarse de sangre (a través de las relaciones sexuales continuas y la alimentación) es la anterior, cuando la carne del feto se está for-

10 Cualidad transferida, mediante una especie de contagio mágico, a una persona por un humano, un animal, una planta, un elemento natural o un ser sobrenatural. A veces, la cutipa afecta directamente a la persona que ha realizado algo indebido (comer un animal determinado, por ejemplo), y otras, a los hijos de ella (Chirif, 2016).

11 Las vitaminas a las que hace mención son pastillas de hierro.

12 Centro de salud.

13 En castellano regional se usa «para» para decir «se queda». 
mando. En esta etapa las mujeres se cuidan de no engordar mucho y de no comer ciertos alimentos que pueden afectar al niño por la cantidad de pora que contienen. Cuando el personal de salud les dice que esas vitaminas les van a dar sangre, en lugar de motivarlas para que las tomen, las asusta debido a que desde la concepción ticuna llenarse de sangre es engordar y un bebé muy grande es difícil de parir. Al respecto, Belaunde (2017) explica que para los pueblos indígenas amazónicos:

Comer animales con mucha sangre y grasa es muy peligroso en los momentos de transformación, porque son animales que tienen espíritus fuertes y te pueden cutipar y su olor ahuyenta a los espíritus positivos. Además, en el caso ticuna el pora es crucial y los alimentos afectan directamente el pora (que es un aspecto decisivo de lo que nosotros traduciríamos por sangre pero que en el caso ticuna es muy complejo) $)^{14}$.

Las mujeres con las que trabajé a lo largo de tres años me contaban que las abuelas siempre han prohibido comer carne de pelejo (perezoso) por miedo a la cutipa. Dalia, mujer de 35 años, madre de cuatro niños comentó:

No comes algo que le puede cutipar, por ejemplo, el pelejo. Si tú le ves al pelejo, no le asquees. No es que no le comes, sino que no le asquees, o cuando le ves vivo, no le digas feo, porque si no igualito sale tu hijo.

Debido a que tanto la madre como el padre influyen en la formación física y conductual del feto (Rivas, 2004), el padre también debe cumplir ciertas conductas durante el embarazo. Al respecto, una mujer ticuna me contó que los padres deben tener cuidado de no matar ciertos animales durante la gestación, ya que puede afectar al feto.

La lombriz tampoco se toca. Eso también cutipa, se retuerce, los que anzuelean ${ }^{15}$ con lombriz. El suri ${ }^{16}$, no puedes ni comer ni tocarle porque el niño se retuerce. Cuando hallan víbora, no le matan a la víbora porque si no sale ya cutipado. Su papá no puede matar víbora, boa, el tigre. Ahí le cutipa, pues. Cuando nace tampoco. Un mes así.

La preparación al parto

Esta etapa también está acompañada por las parteras o sobadoras de barriga, quienes se aseguran de colocar al bebé en la posición adecuada mediante frotaciones

\footnotetext{
14 Comunicación personal a través de mi cuenta de Facebook. Fecha:14 de junio 2017.

15 Pescar con anzuelo.

16 Gusano que crece en los troncos de las palmeras caídas.
} 
con algunos aceites y grasas, como el aceite de andiroba (Carapa guianensis), manteca de gallina negra, de lagarto o de raya y el huevo de gallina.

Hortensia, una partera de la comunidad Santa Rita de Mochila, me contó que es necesario que «desde los tres meses se empieza a sobar la barriga para que puedas tener normal». Otra mujer que estaba atenta a la conversación dijo: «Mi hijo estaba atravesado. La partera me ha sobado, duele [...] estaba mal, pues». Asimismo, otra mujer contó que cuando ella estaba embarazada, su madre la cuidaba mediante frotaciones para que no sufriera al dar a luz: «Te soban tu barriga con manteca de raya cuando ya va nacer para que no sufras».

Otra práctica muy conocida en varios pueblos amazónicos es la de la ligada o vaporización de cuerpo, que tiene mucha relación con el manejo de lo frío y lo caliente. Se trata de sacar el frío del cuerpo de la embarazada por medio del vapor de ciertas plantas.

Cuando estás de cinco meses por arriba, se liga. Cada mes, dos meses. A veces cuando te duele tu barriga a cada rato es porque hace mucho frío. Ahí te empiezan a ligar. Mi mamá me ligaba con hoja de plátano seco y hoja de santa maría ${ }^{17}$.

Para hacer la ligazón, las plantas se ponen en una bandeja con agua caliente. La embarazada puede colocarse con las piernas abiertas para recibir el vapor o sentarse dentro de la bandeja cuando el agua está tibia.

El chamán también cumple una función importante en esta etapa. Él se encarga de soplar la barriga de la embarazada con humo de tabaco para asegurar la posición correcta para el alumbramiento.

\section{El alumbramiento}

Cuando llegan los dolores de parto, la mujer toma infusiones que la ayudan a parir rápido y sin mucho dolor, como infusión de hoja de algodón, de hojas de ají o de pepas de cacao rallado, café cargado, jengibre u otras. Además, toma huevo crudo, la flema de la malva ${ }^{18} \mathrm{y}$ aceite vegetal o grasa de raya para ayudar a que el bebé resbale y salga pronto. La grasa de raya también se usa para sobar la cintura de la mujer en el proceso de parto y aliviar su dolor.

[Se toma] algodón cuando va nacer. Te dan de tomar hoja de algodón para que nazca rápido el bebé. Te soban tu barriga con manteca de raya cuando ya va a nacer para que no sufras (Dalia).

17 Piper peltatum $L$.

18 Malva sylvestris. Planta que al estrujarla en agua genera una sustancia flemosa. 
Una de las señales para saber que ya vas a dar a luz es que la corona de la cabeza se calienta. Una profesora de la comunidad Santa Cecilia me contó:

Cuando estaba embarazada viene ella [refiriéndose a su cuñada] y me dice «levántate ya, tu cabeza está caliente, tienes que ir al hospital». «¿Qué pasa con mi cabeza?». «No, ya vas a dar a luz». Y de verdad eso es una señal, porque ahí mismo me llevaron al hospital y apenas llegué estaba dando a luz.

Si existen complicaciones durante el parto, en algunos casos la mujer es evacuada al centro de salud de Caballococha. En otros, en caso que exista chamán en la comunidad, este sopla humo de tabaco en la corona de la mujer para facilitar el alumbramiento. Por lo general las mujeres atribuyen las complicaciones del parto al incumplimiento de las dietas y los consejos de sus madres desde que son pequeñas.

Son diversas las posiciones de parto que me han explicado las mujeres ticuna; sin embargo, absolutamente todas son en posición vertical. Muy pocas veces van al hospital, ya que tienen miedo a que las «hagan echar» o las corten. Las posiciones más frecuentes para dar a luz son en cuclillas, sostenidas por detrás por el marido, partera, madre o alguna mujer cercana o familiar, o sostenidas de la hamaca o del horcón ${ }^{19}$ de la casa o de rodillas. A pesar de que muchas mujeres (sobre todo las más jóvenes) manifestaron que prefieren dar a luz acompañadas por sus maridos, madres, suegras o hermanas, hubo una que me dijo que a ella le daba mucha vergüenza parir delante de la gente.

Yo solo he tenido ayuda en mi primer hijito. Ahí me ha ayudado mi marido. Después de eso, yo he dado a luz sola ${ }^{20}$.

¿Y por qué querías dar a luz sola?

Porque me daba vergüenza, profesora. Yo no quería que nadie me esté viendo hacer fuerza (pujando). Cuando ha nacido este mi segundo, yo he agarrado mis cosas y vamos, me he ido lejos. Cuando ha nacido, yo he regresado.

Esto me recuerda a una abuela yagua, quien durante una visita a su comunidad me comentó que antiguamente las mujeres iban a dar a luz al monte, ya que la sangre del parto es sucia y contamina a los cazadores. Ella me contaba muy molesta que ahora «todas son unas cochinas», ya que daban a luz en sus casas. Tal como lo expresa Mahecha, antiguamente los hombres no podían estar en el momento del alumbramiento, pues la sangre de la mujer podía contaminarlos

19 Columna de madera que sostiene la casa.

20 Se presenta en letra normal lo que dice mi interlocutora y en negrita lo que digo yo. 
(Mahecha, 2015). En general, explica Belaunde (2001), «toda la sangre que sale del cuerpo es considerada como una forma de suciedad y las personas tienen mucho cuidado de lavar todo rastro de sangre y evitar el contacto con la comida».

- Cuarta etapa (después del alumbramiento y los primeros dos meses del bebé) que se caracteriza por descansar y la «humanización» del bebé: parto o taxrüng $\tilde{u}$ «descansa» o ta ixraacü «ya nació su bebito».

Cuando nace el niño, se espera que la placenta se desprenda para cortar el cordón umbilical que es llamado na-ã, que significa literalmente «la boca» (Goulard, 2009). La madrina lo corta con un pedazo de izana (Gynerium sagittatum) ${ }^{21}$, aunque actualmente utilizan hojas de afeitar o tijeras. La madrina o cortadora antiguamente pertenecía a la mitad opuesta del niño (Goulard, 2009). Sin embargo, hoy en día esta tarea puede ser realizada por la abuela, como veremos más adelante. La verdadera inscripción del bebé como ser vivo es cuando se le atribuye el nombre, lo que se realiza antes del corte del cordón umbilical. El niño se asocia a lo vegetal y con el nombre clánico se le humaniza (Goulard, 2009). Una mujer me contó que apenas nace el bebé se le confirma su clan:

Al momento de nacer, la abuelita, desde que nace, dice qué bonito mi nieto, y le pone su clan. Si no está la abuela, tiene que ser otra abuela con experiencia que le da el clan de su papá. Las personas del mismo clan no se pueden enamorar, no se pueden casar. Tú reconoces a tu clan, aunque sea clan paujil de Brasil, igual es tu familia si tú eres un paujil. Los que tienen pluma no pueden casarse con los de pluma, tienen que casarse con sin pluma. Si es de tu clan, es tu familia, tu tía, tu prima.

Santos (2014) explica que antes de cortar el cordón se busca un nombre de acuerdo con el clan patrilineal. Cuando se nombra el clan, se atribuye a la persona una característica del animal o vegetal que representa el clan. Un abuelo de la comunidad Santa Cecilia me explicó:

Por ejemplo, si era paujil, le decían dexparana «canilla amarilla» si es mujer y si es varón dauraũna «nariz roja». Si tu clan es tigre, te dice düeüku, que es una característica del tigre que come una presa y guarda un poco, y si es mujer le dicen «color bonito».

21 Un tipo de caña que algunos pueblos indígenas utilizan para hacer puntas de flechas. 


\section{La protección del bebé}

Inmediatamente después de la atribución clánica, la madre unta el cuerpo del bebé con huito, ya que la tintura negra de este fruto elimina todo rastro del olor de sangre del parto que los vuelve visibles ante los ojos de los ngo-o (Belaunde, 2016; Goulard, 2009; Santos, 2014). Goulard (2009) señala que uno de sus informantes manifestó que se le tiene que pintar «para que desaparezca el olor que tiene el niño. Tiene un olor a sangre de animal descuartizado. Si no se hace, cuando el niño vaya al monte o al río es contaminado» (Goulard, 2009, p. 140). La madre también deberá pintarse el cuerpo con huito para eliminar el olor del parto. Además, al bebé se le coloca pulseras con huayruros (Ormosia coccinea) rojos o de botón rojo para protegerlo del «mal de ojo». Por otro lado, les colocan collares para que no se enfermen, como el de pepitas y uñas de carachupa (Dasypus novemcinctus ${ }^{22,}$ huesito de zorro para que no se fracture los huesos con facilidad y el de misho ishma ${ }^{23}$ para evitar la gripe (Rivas, 2016).

La placenta y el cordón por lo general son enterrados debajo de árboles considerados fuertes, como el ubos (Spondias mombin L.). Una abuela me decía «ese árbol no sabe morir. Por eso le enterramos ahí, para que el bebé sea fuerte y tenga mucha vida».

Después del nacimiento del bebé los padres seguirán las restricciones alimenticias, conductuales y sexuales necesarias para garantizar su bienestar. Las restricciones que los padres deben cumplir en este periodo están relacionadas con evitar actividades que impliquen tocar resinas, porque se le tapará la nariz al bebé, exprimir sus pañales durante los tres primeros meses porque el bebé se retorcerá. El papá no puede «tocar ni jugar con la pelota porque se le hinchará la barriga, no deberá tocar o matar serpientes porque le saldrán heridas en su cuerpo». La mamá «no deberá comer pez zúngaro porque le causará diarreas». Tampoco «deberán comer lagarto porque si no el bebé no dormirá. No deberá sentarse en una catahua (Hura crepitans) ${ }^{24}$ para lavar ni pasar por debajo de este árbol porque le saldrán granos al bebé». Con relación a la alimentación, la madre deberá comer alimentos desprovistos de pora, es decir, con poca grasa y sangre debido a que el bebé tiene poco pora al nacer y la madre podría transmitirle gran cantidad de pora a través de la leche materna.

\footnotetext{
22 Conocido también como armadillo.

23 Semilla de olor muy fuerte. Isma es palabra quechua que significa excremento y misho es la manera de referirse al gato.

24 Árbol.
} 
La protección del bebé también implica que la madre permanezca en casa y limite su actividad física, ya que ciertas tareas podrían enfermarla de sobreparto ${ }^{25}$. Por esto, durante un mes no podrá tocar ni tomar nada frío. Dalia me comentó que ella fue curada del sobreparto con corteza de ubos y otras plantas que ayudan a cicatrizar el vientre. Para cuidarse de esta enfermedad las mujeres, tan pronto dan a luz, se amarran una tela en la cabeza, se colocan algodón en los oídos y calcetines en los pies. Esto evita que les entre frío.

Rosmery $^{26}$ me explicó qué es lo que sucede si no cumplen con la dieta y la prohibición de la reclusión.

Bujurqui ${ }^{27}$, eso vas a comer. Si tú comes paña ${ }^{28}$ vas a hacer hemorragia u otras enfermedades te van agarrar cuando nazca el bebé. No vas a tomar agua fría, cuando vas a salir, tú tienes que amarrar tu cabeza, poner medias ${ }^{29}$, pantalón, manga larga ${ }^{30}$ para que proteja, pues, al bebé también. El bebé no vas a sacar así nomás, tienes que abrigarle bien.

¿Qué pasa si sales de casa con el bebé así nomás?

Se enferma con fiebre, gripe, diarrea (este...) o algo les cutipe.

¿Quién le cutipa ${ }^{31}$ ?

Mal de aire, más que todo mal de aire, o uno sale y pisa donde pasa la víbora, eso...

Luego me explica que, cuando se cumple el tiempo de reclusión, el chamán espolvorea cenizas desde la casa hasta el río. Esto protegerá a la mamá de la cutipa o, tal como dice el abuelo ticuna Paulino Santos, «esto se realiza para que el frío no entre en su cuerpo. Después de este paso ella puede ir a bañarse sin temor» (Santos, 2014, p. 339).

Rosmery continúa:

25 Infección causada después del parto que se manifiesta con escalofríos, fiebres y sangrado vaginal. Esto puede llevar a la muerte de la mujer.

26 Se presenta en letra normal lo que dice mi interlocutora y en cursiva lo que digo yo.

27 Biotodoma Cupido. Pez que habita en pantanos y aguas estancadas.

28 Piraña.

29 Calcetines.

30 Se refiere a camisa de mangas largas.

31 (Del quech. kutiy, regresar.) Cualidad transferida, mediante una especie de contagio mágico, a una persona por un humano, un animal, una planta, un elemento natural o un ser sobrenatural. A veces la cutipa afecta directamente a la persona que ha realizado algo indebido (comer un animal determinado, por ejemplo), y otras, a los hijos de ella. Cuando una madre gestante o un padre comen ciertos alimentos, estos pueden transmitir sus cualidades al bebé en gestación o al recién nacido (Chirif, 2016). 
Un curioso, el papá le llama a un curioso para que le cura, pues, con esa ceniza. Le lleva así poniendo y la mamá le pisa así donde que pone la ceniza, así de camino al puerto para que no le cutipe, dice, el bufeo o cualquier animal del río o del agua, pues. Para eso, dice, es bueno eso.

¿Y esto es cuando las mamás han dado a luz?

¡Ajá! Cuando después de [dar a] luz ya, pues, cuando ya va salir, ya cuando salga primer día pues, cuando se vaya al puerto.

¿Y es para que no le cutipe a la mamá o al bebé?

A la mamá, porque la mamá está su cuerpo como un bebé, que dicen. Su cuerpo está suave.

¿Y qué le pasa?

Le duele su vejiga o tiene fiebre. Eso dice, cómo puedo decir, los animales dice que le balea, los animales dice.

¿Y cómo se cura cuando la mamá se cutipa?

Le llama a los curanderos para que le cure ya, ahí ya se sana.

Un punto interesante de notar es que ella se refiere a que la mamá, después de dar a luz, tiene el cuerpo suave como el de un bebé. Un abuelo ticuna le explica a Santos que la mujer «debe estar resguardada con su bebé, para que su cuerpo madure porque está verde, los ngaite $^{32}$ están al acecho por él y ella» (Santos, 2014, p. 335). Asimismo, cuando ella se refiere a que «los animales balean» significa que estos transmiten daño a través de los virotes mágicos (dardos mágicos). Tema tratado por Jean Pierre Chaumeil (1994), quien investigó temas de chamanismo entre los yagua.

Al bebé recién nacido se le llama dauchara, que significa «coloradito, rojito». Después son llamados õchana o también õõ, que significa bebé pequeñito y va desde que nacen hasta los dieciocho meses. En esta fase el bebé es tan frágil que necesita «toda la atención necesaria para cultivar en su cuerpo todos los principios vitales que se irán fortaleciendo a medida que reciba buena alimentación, adecuados consejos, conocimiento y todos los remedios necesarios para la protección, curación y ordenación del cuerpo físico y cósmico» (Santos, 2014, p. 338).

Durante el periodo de reclusión, el cuerpo del bebé se va formando y fortaleciendo. A través de sustancias como la leche materna y el sudor, el bebé se consustancializa de estas sustancias humanas que, tal como manifiesta Mahecha (2015: 208), «conformarán sus cuerpos, espíritus y bancos de pensamiento». Así, por ejemplo, una abuela me comentó que cuando su nieto nació, el papá lo envolvió en su camisa sudada para que sea fuerte y no se enferme rápido. De esa

\footnotetext{
32 Espíritus malignos.
} 
manera le transfiere sus habilidades. El compartir sustancias, como la comida, los fluidos corporales o los olores, es lo que construye a la persona amerindia. Además, en el caso ticuna, õchana permanecerá pegado a su madre durante toda esta etapa (aproximadamente hasta el año y medio) mediante el nachimû (literalmente piel) (Goulard, 2009), que es una banda tejida. Mediante ella la madre lo tendrá cargado todo el tiempo en su cadera. En este periodo, la madre marca a su bebé a través de una serie de comportamientos, como el transporte y la alimentación: «notemos que la necesidad de 'marcar' había empezado al momento del nacimiento con la atribución del nombre» (Goulard, 2009, p. 146). De esta manera, se asegura cada vez más el principio vital, $a-e$.

Los principios corporales y la humanización del bebé

Entonces, la inscripción al mundo de los humanos se establece a través del corte del cordón umbilical y la atribución clánica. Esto hace que el niño se humanice. La identidad individual y clánica es determinada por el $m a-\tilde{u}$ (principio corporal). A pesar de que el $m a-\tilde{u}$ se establece desde el nacimiento (sin esto no es posible la existencia), este se perpetúa a partir de las constantes dadas por el nombre clánico. Es decir, las características del clan al que pertenece, representado por los diferentes atributos (pluma, cola, etcétera) o cualidades (tipo de vuelo, posturas, colores).

Para garantizar la protección del bebé, los padres seguirán un conjunto de dietas, restricciones conductuales y sexuales. Es así como, a través de la dieta de los padres, y sobre todo de las madres, se irá fortaleciendo pora del bebé de manera paulatina. Los rituales también se realizan para asegurar la protección del principio vital, $a-e$, asociado al pora. Recordemos que el principio vital $a-e$ no existe sin el pora, ya que este último es el que le da fuerza al cuerpo. Para asegurar el principio vital $a-e$, los padres realizan cierto tipo de «marcación» que está relacionada con el transporte del bebé, la alimentación, los adornos protectores, la pintada con huito y el contacto con los fluidos corporales como el sudor.

\section{REFLEXIONES FINALES}

A lo largo de este artículo he tratado de demostrar cómo la construcción de la persona tiene lugar en el cuerpo y cómo esta se va formando según las concepciones del pueblo ticuna. En este colectivo se involucran distintos seres del cosmos, que forman parte de un universo social compartido, desde visiones indígenas que no 
oponen lo humano y no humano, como sí lo hace occidente. En este sentido la persona no solo se crea por agencia humana, sino también con la participación e influencia de diversos seres.

La construcción colectiva del cuerpo ticuna se ve reflejada a través de los rituales de nacimiento, con la pintada de huito y el de la woxrexcüchiga. La construcción de la persona también supone la consustancialización (compartir sustancias que te hacen parte del mundo humano) y de los consejos.

El objetivo del trabajo, basado en datos etnográficos recogidos en mi investigación etnográfica realizada entre 2013-2016 y contrastada con reciente información etnográfica, ha sido comprender la visión ticuna de la persona tomando como marco referencial el proceso procreativo, cuando se construye la persona y el cuerpo desde el inicio de la vida. Los resultados de esta investigación confirman lo que ya han afirmado algunos antropólogos sobre los pueblos indígenas amazónicos. Sin embargo, la perspectiva analítica utilizada en este trabajo ha permitido matizar algunos aspectos procreativos interesantes que pueden contribuir a ampliar la concepción ticuna sobre la procreación y la noción de persona que se asume como la construcción de la corporalidad.

Si bien las nociones ticuna han sido estudiadas por Goulard (2009), es cierto que el análisis procesual permite entender todos los cambios que se producen en los tres principios (ma-ũ, $a-e$, pora) que ocupan un lugar central a lo largo de todo el proceso procreativo, así como: prescripciones, prohibiciones, prácticas curativas, preventivas y rituales, en cada momento. Estudiar el proceso procreativo a partir de la experiencia de las mujeres posibilita llegar a su nivel de interpretación, abarcando todo aquello que practican, piensan, les preocupa, les interesa, entienden, imaginan, comparten y les provoca conflicto. Pero, sobre todo, abre el campo de entendimiento de la importancia sobre cómo la persona se va humanizando a partir de su diferenciación de los otros seres del cosmos: la confirmación clánica, la pintada con huito, los adornos corporales, las escarificaciones y el compartir sustancias constituyen la perspectiva diferenciadora. Así también la fragmentación del proceso siguiendo la visión ticuna en cuatro periodos - concepción, barriga pequeña, barriga grande, y descanso/ya nació-, iniciándose el cuarto a partir de la escisión del cordón umbilical, alejándose de la visión biomédica que lo definiría según embarazo, parto y postparto.

Es a partir del análisis procesual que se entiende cómo al principio el bebé es conceptualizado como vegetal; con el alumbramiento, él empezará a humanizarse. Para subsistir durante este periodo no necesita alimentos con exceso de pora, sino de la colaboración de sangres, la de su madre y la de su padre (semen) que 
lo fortalezcan mínimamente. De aquí que durante este periodo la mayor parte de las prescripciones y prohibiciones estén encaminadas a no contaminar las sangres que lo están formando.

Su humanización se produce a partir del corte del cordón umbilical (ña-a, la boca) y con la atribución del nombre, que confirmará el clan patrilineal. El nombre clánico es el que lo ubica en una mitad (con plumas o sin plumas) y lo que le permite la estabilización social dentro de la colectividad ticuna. Aunque el proceso para humanizarlo continuará a través del compartir sustancias como alimentos y fluidos corporales tales como la leche y el sudor. De hecho, es a partir de este momento como se va definiendo la corporalidad para ubicarlo en el terreno de lo humano. Para proteger el $a$-e del recién nacido, la madre pinta todo su cuerpo $(m a-\tilde{u})$ con huito o genipa; de esta manera evita que los ngo-o, quienes se sienten atraídos por el olor a sangre, lo lleven a su mundo. Con relación al pora es solo a partir de entonces que este se irá incrementando paulatinamente, haciéndolo menos vulnerable a las agresiones de los seres del cosmos. La introducción del recién nacido entre los humanos obliga a los padres a cumplir con una serie de restricciones y prohibiciones. La más importante es sin duda la reclusión: primero dentro del toldillo o hamaca, luego la madre podrá desplazarse por la casa y el padre podrá salir de casa a hacer algunas tareas mínimas.

Finalmente, quisiera añadir que los resultados de esta investigación confirman lo que ya han afirmado las investigaciones desarrolladas por otros antropólogos en pueblos indígenas amazónicos, quienes sostienen que las mujeres prefieren dar a luz en sus comunidades y tienen miedo de parir en el hospital debido a que reciben maltrato, no les permiten dar a luz en posición vertical y les hacen la episiotomía (corte entre la vagina y el ano). Esto me lleva a pensar en la necesidad de incorporar en los servicios de atención médica, sobre todo en aquellos que funcionan en zonas indígenas, las concepciones nativas sobre menstruación, fertilidad, procreación y cuidados del recién nacido. A pesar de que se ha intentado integrar a las parteras dentro de los sistemas de salud pública, los resultados no han sido los mejores debido a que era un trabajo voluntario y esto generaba descontento entre las especialistas indígenas, quienes consideraban que el hecho de no remunerarlas, invisibilizaba la importancia de su labor respecto del saber médico occidental.

En esta misma línea, considero que los programas materno-infantiles deberían incorporar las nociones indígenas sobre los cuidados prenatales y de gestación, diversificando las dietas adecuadas para las madres gestantes ya que pude observar que los especialistas de salud recomiendan que las madres se alimenten con 
platos elaborados con sangre de pollo o de vaca, como «sangrecita» ${ }^{33}$, debido a que evita la anemia. Sin embargo, tal como manifiestan diversos antropólogos, y a través de mi convivencia con los ticuna, las mujeres gestantes o parturientas evitan comer animales con mucha sangre debido a afecta el equilibrio del flujo de sangre del bebé. Para los ticuna una cantidad de pora muy alta en un ser en crecimiento puede ser nefasta. Además, he podido confirmar, a través del testimonio de las mujeres, que durante el embarazo evitan tomar los medicamentos que brinda el sistema de salud debido al temor de que el niño engorde, ya que «esas pastillas te dan sangre». Esto me ha causado gran interés y considero que debería ser tema de trabajo en futuras investigaciones con el pueblo ticuna, ya que diversos antropólogos americanistas dan cuenta de la importancia que tiene el flujo y derramamiento de sangre para los pueblos indígenas.

\section{REFERENCIAS}

Belaunde, Luisa Elvira (2008). El recuerdo de Luna. Género, sangre y memoria entre los pueblos amazónicos (segunda ed.). Lima: CAAAP.

Belaunde, Luisa Elvira (2016). Los rituales de la pubertad femenina en la Amazonía. En M. de Cultura (ed.), Woxrexcuchiga. El ritual de la pubertad del pueblo ticuna (pp. 13-43). Lima: Ministerio de Cultura.

Berjón, Manuel M. y Miguel Ángel Cadenas (2014). Inestabilidad ontológica: el caso de los kukama de la amazonía peruana. OALA, 1-25. Recuperado de http://www. oalagustinos.org/pdf/2014_15Manuel.pdf

Chaumeil, Jean-Pierre (1994). Los yagua. En F. Santos y F. Barclay (eds.), Guía Etnográfica de la Alta Amazonía (Volumen I). Quito: FLACSO.

Chirif, Alberto (2016). Diccionario amazónico. Voces del castellano de la selva peruana (Centro Amazónico de Antropología y Aplicación Práctica, Ed.). Lima: Lluvia.

Fons, Virginia, Irina Casado, Elixabete Imaz, Sara Lázare y Meritxell Sáez (2019). Cronografías procreativas. Ejemplos etnográficos analizados desde una nueva perspectiva. Revista de Antropología Iberoamericana, 14(3), 389-415. Recuperado de https://www.aibr.org/antropologia/netesp/numeros/1403/140303.pdf

Formabiap (2008). Currículo de Educación Inicial Intercultural Bilingüe. Pueblo Kukama-Kukamiria. Construyendo participativamente la educación que queremos. Iquitos: AIDESEP.

33 La sangrecita es una entrada que se prepara utilizando la sangre cocida de algunos animales como la gallina, cabrito, res o pavo. 
Goulard, Jean-Pierre (1994). Los ticuna. En F. Santos y F. Barclay (eds.), Guía Etnográfica de la Alta Amazonía. Quito-Ecuador: FLACSO.

Goulard, Jean-Pierre (2009). Entre mortales e inmortales. El ser según los ticuna de la Amazonía,. Lima: CAAAP-IFEA. https://doi.org/10.4000/books.ifea.3927

Lázare, Sara y Virginia Fons (2016). Los procesos procreativos desde la Antropología: el caso de las madres de Barcelona por un parto respetado. Instituto Catalan de Antropología, 21(2), 21-37. Recuperado de https://www.raco.cat/index.php/ QuadernseICA/article/view/320535

Rivas, R. (2004). La serpiente, madre del agua (tesis doctoral). Ecole des Hautes Etudes en Sciences Sociales, EHESS, París-Francia.

Rivas, Roxani (2016). Prácticas de crianza en niños menores de 3 años de los pueblos tikuna, yagua y kukama. Lima: MINEDU-OEA.

Santos, Abel (2014). La constitución de naüne (cuerpo) entre los yunatügü (tikuna). Mundo Amazónico, 5, 327-356. https://doi.org/10.15446/ma.v5.45753

Seeger, Anthony, Roberto Da Matta y Eduardo Viveiros del Castro (1987). A construção da pessoa nas sociedades indígenas no Brasil. En J. Oliveira Pacheco (ed.), Sociedades indígenas \& indigenismo no Brasil (pp. 11-29). Río de Janeiro: UFRJ Marco Zero.

Tassinari, Antonella y Camila Guedes Codonho (2015). Al ritmo de la comunidad: enseñanza y aprendizaje entre niños indígenas galibi-marworno. Anthropologica, 35, 173-203. Recuperado de http://revistas.pucp.edu.pe/index.php/anthropologica/ article/view/14641/15227

Tola, Florencia (2012). El cuerpo múltiple qom en un universo superpoblado. Indiana, 5(2012), 303-328. Recuperado de http://f.hypotheses.org/wp-content/blogs. dir/1194/files/2013/03/Tola-el-cuerpo.pdf

Vieco, Juan José, Carlos Eduardo Franky y Juan Álvaro Echeverri (2000). Territorialidad indígena y ordenamiento en la Amazonia. Leticia: Universidad Nacional de Colombia.

Viveiros de Casto, Eduardo (2004). Perspectivismo y multinaturalismo en la América Indígena. En P. García y A. Surrallés (eds.), Tierra adentro. Territorio indígena y percepción del entorno (pp. 37-77). Copenhague: IWGIA. 